\title{
Small and flat worlds: A complex network analysis of international trade in crude oil
}

\author{
Yu Yang ${ }^{\text {a, * }}$, Jessie P.H. Poon ${ }^{\text {b }}$, Yi Liu a , Sharmistha Bagchi-Sen ${ }^{\text {b }}$ \\ a Institute of Geographical Sciences and Nature Resources Research, Chinese Academy of Sciences, Beijing, 100101, China \\ ${ }^{\mathrm{b}}$ Department of Geography, University at Buffalo-SUNY, Buffalo, NY 14261, USA
}

\section{A R T I C L E I N F O}

\section{Article history:}

Received 24 February 2015

Received in revised form

1 August 2015

Accepted 16 September 2015

Available online 22 October 2015

\section{Keywords:}

Crude oil trade

Small world

Flat world

Complex networks

GIS (geographical information system)

\begin{abstract}
A B S T R A C T
Global competition for crude oil has increased in the past decade with the entry of industrializing nations such as China and India. Yet we still do not know much about the spatial structure of crude oil commodity trade and its evolution over time. In this paper, we apply complex network analysis to examine the geography of global crude oil flows and its evolution based on the United Nations commodity trade database from 1988 to 2013. Attention is given to the geo-visualization of the networks that trace the rise and decline of oil hubs. The results show that world crude oil is characterized by network characteristics that capture both small world and flat world properties.
\end{abstract}

() 2015 Elsevier Ltd. All rights reserved.

\section{Introduction}

The year 2015 began with a precipitous fall in oil prices to below $\$ 50$ per barrel. Yet oil production has continued unabated by major exporting countries in the Middle East and the United States (US). Fueled by demand as industrial production expanded both in developed countries and developing countries in Asia and Latin America, the value of international trade in oil rose from US\$37 billion in 1988 to US\$1626 billion in 2013. This represents a fortyfold increase in 25 years. Oil is not only a main source of fuel that drives most modern economic activities, but it is also the basis of manufactures such as plastics and fertilizers in the petrochemical industry. As a strategic natural resource, crude oil accounts for $33.5 \%$ of world energy consumption with more than $60 \%$ of global oil consumption being met by imports in the past ten years [1]. Despite its importance in global economic outlook, not much work has been done on crude oil trade with few exceptions (see below). This paper seeks to augment this body of work by examining the spatial dynamics of the international trade of crude oil through the integration of GIS (geographical information system) and complex networks. Network analysis has gained popularity because of its

\footnotetext{
* Corresponding author.

E-mail addresses: yangyu@igsnrr.ac.cn, ucasyu@gmail.com (Y. Yang).
}

ability to represent the world trading system through the organization of spatial attributes [2]. It is useful for capturing the level of connectivity between countries [3]. Applying complex network model allows us to examine the changing structure of oil trade over time. A scale-free network perspective draws attention to the interconnections between countries [4,5]. Integrating GIS with networks facilitates the geo-visualization of international oil trade in graphical representations.

In general, empirical studies of the spatial dynamics of trade have shown that the international trading system has become more interconnected over the past three decades [6,7]. Nonetheless, they also found that the system tends to be composed of small-worlds the idea that people, firms and countries are highly connected. The small world phenomenon may be traced to social psychologist Stanley Milgram as well as Watts and Strogatz who showed that the number of connections or edges between two nodes is fairly short on average $[8,9]$. Specifically, they found that the average number of intermediaries from a sender (originating country) to target receiver (destination country) is about six leading to the general rule that two nodes are characterized by six degrees of separation. In other words, the small world phenomenon describes a locally clustered network structure with a short path length between two otherwise divergent network characteristics. The relevance of the small world phenomenon is that it can potentially shed light on trade behavior by shaping the level of connectivity among 
countries embedded in the world trading system. The more a network displays small world characteristics, the higher the level of connection between countries implying a deepening collaboration with one another or through a third common country [10]. This facilitates trade circulation in clusters that are otherwise separate increasing the likelihood that resources from one cluster may be accessible or shared by another cluster. In the context of trade, clustering also leads to the regionalization of supply chains to capture the advantages of regional economies of scale and lower transaction costs among firms [11,12].

At the same time, international production is increasingly spatially fragmented across GVCs (global value chains) as firm exploit locational differences in factor endowments and regulatory environments. Suppliers and subcontractors in developing countries are joining the world trading system by participating in GVCs [13]. The export volume of developing countries for instance doubled between 2000 and 2008 compared to a 50\% increase of world exports over the same period (www.WTO.org). Participation of a greater number of countries in international trade is accompanied by geographical diversification of trade relationships, a flatter world as Thomas Friedman has suggested [14]. In contrast to small world that stresses the spatial proximity of trade connections, flatter worlds are consistent with a more globalized world economy, a larger world that is driven by trade connections over longer distances or spatially dispersed locations $[15,16]$. The flat world thesis was first proposed by O'Brien over twenty years ago [17]. He concluded that distance has become an irrelevant barrier for investment and trade in the age of globalization. A country can trade with partners that are located farther away as transportation costs have fallen. The world topography has effectively become flatter because firms are highly mobile in space and can relocate their facilities to distant countries to exploit lower costs, source for inputs, or explore new markets. The relocation of factories, warehouses or logistical centers to far-flung countries in turn generates more connections between countries that result in a flatter world. The crude oil trade is especially global in geographical scope because it is not a ubiquitous resources. It is geographically concentrated in a few countries although technology has uncovered new sources in non-traditional areas [18]. Demand for oil however is spatially dispersed generating more connections in long distance trade for example between the Middle East and East Asia.

Under a complex network approach, oil trade spatial structure is examined in terms of the degree and strength of connectivity between countries; hence the focus is on how oil flows are distributed across the network. Some studies found evidence of small world properties [12,19]. Others have shown the opposite, that is, trade is more spatially diffused [20]. In the oil trade, there appears to be support for increased global connectivity [21]. This paper contributes to the literature by integrating both small and flat world approaches through complex network analysis and GIS geovisualization. Some countries, for example those in NAFTA and EU, establish trade clusters with nearby countries because they share a common culture and history. Firms are likely to be more familiar with the needs of neighboring markets and trade more intensively across common borders [11,22]. Others including resource-poor East Asia or small countries may establish trade connections across the globe to source for raw materials like oil. This paper will show that the oil trade landscape is not reduced to one spatial outcome, that is, small or flat world. Rather we hypothesize that both outcomes may be found simultaneously.

In the next section, major network measures are outlined and described. These include indices of network connectivity, centrality and community structure. This is followed by a discussion of the results of network analysis. The paper concludes with a summary of the major findings.

\section{Network measures and data}

\subsection{Network construction}

Under the complex network model, trade relationships between countries may be graphically captured by a collection of vertices (nodes) and edges or links. Networks can be directed or nondirected. In non-directed networks, exporting and importing nodes are indistinguishable in a dyad, and edge direction is of little interest. In the case of a directed network, country A exports to country B, but country B may not export to country A. Likewise, country X imports from country $Y$, but country $Y$ may not import from country $X$. The data indicates that crude oil flows are better captured in directed networks or a diagraph since oil production is highly concentrated spatially. Global crude oil directed network may be represented by a set $G=(V, E)$, such that country nodes $V=$ $\left\{v_{1}, v_{2}, \cdots, v_{n}\right\}$ represent network nodes, and trade relationships set $E=\left\{\mathrm{e}_{i j}\right\}$ denote network edges. $n$ is the number of countries, while $i$ and $j$ are sending and receiving countries respectively ( $i$ and $j$ range from 1 to $n$ respectively). As the analysis will map 1990, 2000 and 2013, $n$ is smallest in 1990 with just 69 countries that are involved in world oil trade. But it increased to 150 countries by 2000 , and remained stable at that size in 2013. The adjacency matrix $\mathrm{e}_{i j}=1$ if node $v_{i}$ exports to node $v_{j}$, otherwise $\mathrm{e}_{i j}=0$. If an edge is established between two nodes, then they are trade partners or geographical neighbors. Since trade volumes vary greatly, such differences should be taken into account. In this paper, we construct crude oil trade flows as the weight of edges. $w_{i j}$ represents export from country $v_{i}$ to country $v_{j}$. If there is no export from $v_{i}$ to $v_{j}$, then $w_{i j}=0$. The weighted directed crude oil network matrix may be given as follows:

$W=\left[\begin{array}{ccc}w_{11} & \cdots & w_{1 m} \\ \vdots & \ddots & \vdots \\ w_{n 1} & \cdots & w_{n m}\end{array}\right]$

\subsection{Network measures}

\subsubsection{Connectivity}

The overall network connectivity may be calculated from two measures. The first is associated with network density indices, and the second with network diameter and length. Network density indices $\alpha, \beta, \gamma$ may be expressed as:

$\alpha=\frac{2(e-v+1)}{(v-1)(v-2)}$

$\beta=\frac{e}{v}$

$\gamma=\frac{2 e}{v(v-1)}$

In (1), (2) and (3), e denotes the edges of the directed network, and $v$ refers to network nodes. $\alpha$ is the ratio of actual to maximal number of circuits in a fully connected network, $\beta$ is the average number of edges per node, and $\gamma$ is the ratio of actual to maximal number of edges [23]. $\alpha$ and $\gamma$ lie between the values of 0 and 1 with 1 being fully connected. In the case of $\beta$ the higher its value, the better connected is the network.

The second connectivity measure is associated with the network's diameter $D$ and average path $L$. Denoting the topological 
distance from node $i$ to $j$ as $d_{i j}$, the diameter is the maximum of $d_{i j}$. In other words, the diameter is the topological distance between the two most remote nodes of the network, and it is calculated using the software Gephi-0.8.2. $L$ refers to the average number of edges along the shortest paths for all possible pairs of nodes in a network [9]. That is to say, L equals the average number of all the shortest paths from a given node to all other nodes. The two indices are:

$D=\max d_{i j}$

$L=\frac{1}{1 / 2 n(n-1)} \sum_{i>j}^{i=n} d_{i j}$

In (5), $\sum_{i>j}^{i=n} d_{i j}$ is the sum of all shortest paths for possible pairs from country vertices $v_{i}$ to $v_{j}$. A smaller value of $D$ and $L$ indicates a better-connected network.

\subsubsection{Network and centrality}

To examine a network's spatial dynamics, we analyze the structure of the oil trade networks over time from 1990 to 2013. The diagraph consists of a set of nodes that represents the countries, and a set of connections or edges [24]. For each edge, crude oil will flow directionally from country i to country j. Three centrality measures may be generated by analyzing the degree $(k)$ of the country node. Degree refers to the extent that two nodes are graphically adjacent (that is, connected) to one another and hence serves as a local point-based centrality measure [25]. In effect, $k$ measures the number of edges in an unweighted matrix. A country with a higher $k$ commands a more important structural position because it has many direct linkages with countries. Put it another way, the country is characterized by a larger neighborhood and is more centrally located. Total nodal degree $k$ may be further divided into in-degree $k_{j}^{\text {in }}$ (importing country node) and out-degree $k_{i}^{\text {out }}$ (exporting country node):

$k_{j}^{\text {in }}=\sum_{i=1}^{n} e_{j i}, k_{i}^{\text {out }}=\sum_{j=1}^{n} e_{i j}$

Under (6), $k_{i}^{\text {in }}$ is the number of edges to a country, $k_{i}^{\text {out }}$ is the number of edges from a country, $n$ is the number of nodes, and $e$ is an element of $E$.

To assign weights to each directed trade relationship, we employ the weighted degree node strength $(S)$ where $S$ is the weighted version of the above nodal degree, and measures the sum of weights of edges for a given country. $s_{i}^{\text {in }}$ and $s_{i}^{\text {out }}$ in (7) below are therefore extended from (6), and $w_{i j}$ is an element of $W$.

$s_{j}^{\text {in }}=\sum_{i=1}^{n} w_{j i}, s_{i}^{\text {out }}=\sum_{j=1}^{n} w_{i j}$

\subsubsection{Community structure}

Community structure may be used to examine both small and flat world properties of crude oil trade exchanges. Under this model, relationships between nodes in the same community are stronger and more stable than relationships between nodes of different communities [26]. In a sense, a community of crude oil members represents the regional or neighborhood structure - that is, small world properties - of oil trade interactions. While it is possible to visually obtain regional neighborhood patterns from centrality measures, the community structure is better quantified based on the notion of modularity [27]. Up to a multiplicative constant, modularity $Q$ refers to the number of edges falling within a group minus the expected number in an equivalent network with edges placed at random [28]. For directed networks, Q is expressed as follows:

$Q=\frac{1}{m} \sum_{i} \sum_{j}\left[w_{i j}-\frac{k_{j}^{\text {in }} k_{i}^{\text {out }}}{m}\right] \delta\left(c_{i}, c_{j}\right)$

where $m=\sum_{i}^{n} k_{i}^{\text {out }}=\sum_{j}^{n} k_{j}^{\text {in }}, \delta\left(c_{i}, c_{j}\right)=\left\{\begin{array}{cc}1 & c_{i}=c_{j} \\ 0 & c_{i} \neq c_{j}\end{array}\right\}, c_{i}$ defines the community which country node $v_{i}$ belongs to, while $c_{j}$ is the community which country node $v_{j}$ belongs to. $\delta\left(c_{i}, c_{j}\right)$ is 1 if country nodes $v_{i}$ and $v_{j}$ are in the same community and 0 otherwise.

\subsubsection{Data}

Data on bilateral crude oil (HS 2709) flows are available from 1988 to 2013 from the United Nations database COMTRADE. HS 2709 includes oils from bituminous minerals and units of measure are available for both net weight and value. This paper uses trade value although similar analyses were also performed for weight and the results are relatively similar. The United Nation trade database provides over 20,000 records of the crude oil flows, but some of the records are trivial with zero or very small values and were thus dropped from the analysis. While 26 networks representing the oil flows of exporting and importing countries from 1988 to 2013 were constructed, only 1990, 2000 and 2013 will be presented for the most parts below to facilitate interpretation and visualization.

\section{Results}

\subsection{Network connectivity}

Overall, the total number of nodes and edges shows an upward tendency over the 1988 to 2013 period (Fig. 1). The number of nodes rose from 50 in 1988 to 150 in 2013, peaking at 173 in 2007. Likewise, the number of edges increased markedly from 134 in 1988 to 1167 in 2011 before falling to 1074 in 2013. Growth of nodes and edges reflects increased participation of countries from new oil producers in Central Asia and Latin America. That an unprecedented number of developing countries embarked on industrialization in this period significantly increased competition for the resource. It is worth noting that major events such as political unrest in the Middle East (US-led war in 2003 and Arab Spring in 2011) slowed the expansion of nodes and edges in 2003, 2012 and 2013. Interestingly such disruption did not happen in the early 1990s despite Iraq's occupation of Kuwait. Crude oil export networks however adjusted quickly as neighboring Gulf countries stepped up their production to offset declining exports from conflict-affected countries. The relative decline of nodes in 2008-2010 is likely explained by the recent financial crisis. Despite this decline, the number of edges remained stable.

Connectivity indices $\alpha, \beta$ and $\gamma$ are presented in Fig. 2a. $\alpha$ 's value was 0.07 in 1988. It peaked at 0.10 in 1990, declined throughout the 2000 s to 0.06 before turning upward again to 0.10 in 2013. Such a trend is mirrored by $\gamma$ which also peaked in 1990 at 0.12 before falling to 0.07 in 2002 . The value of 0.07 remained constant for the next five years rising slightly to 0.08 in 2008 before climbing to 0.10 at the end of the study period. But the $\gamma$ value of 0.10 is however still lower than the 1990 peak. One explanation for their lower values in the early 2000s is that this period was characterized by the expansion of country vertices (from 69 to 150) relative to the expansion of edges. This increased the values of the denominators considerably causing the index to fall. In addition, political and economic turmoil over the period including two major financial 


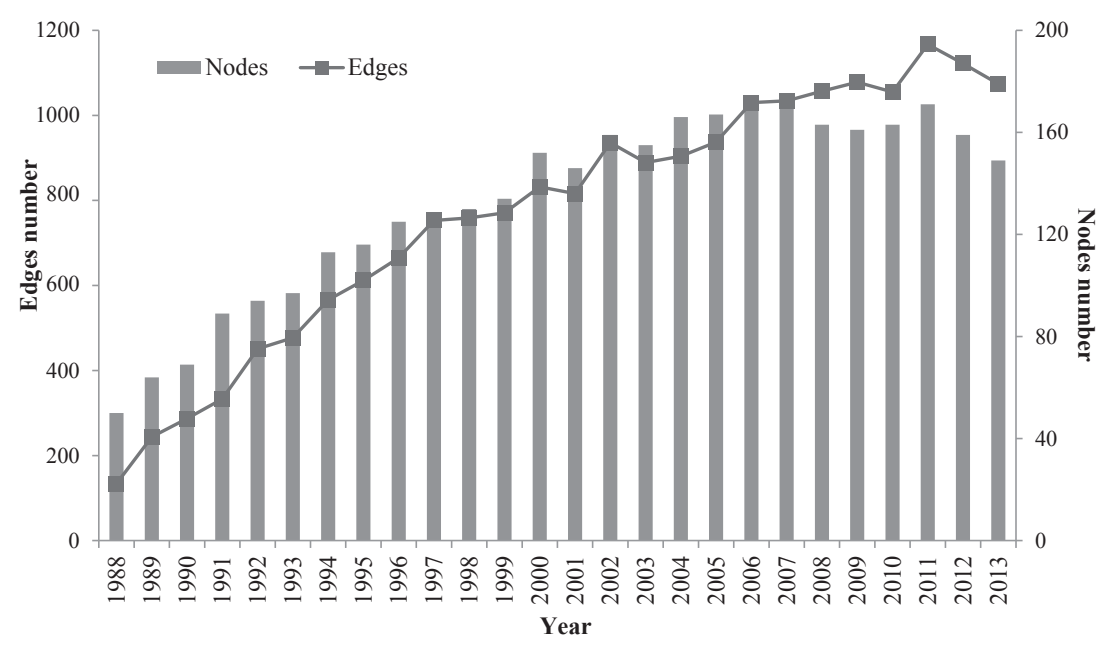

Fig. 1. Number of edges and nodes, 1988-2013.
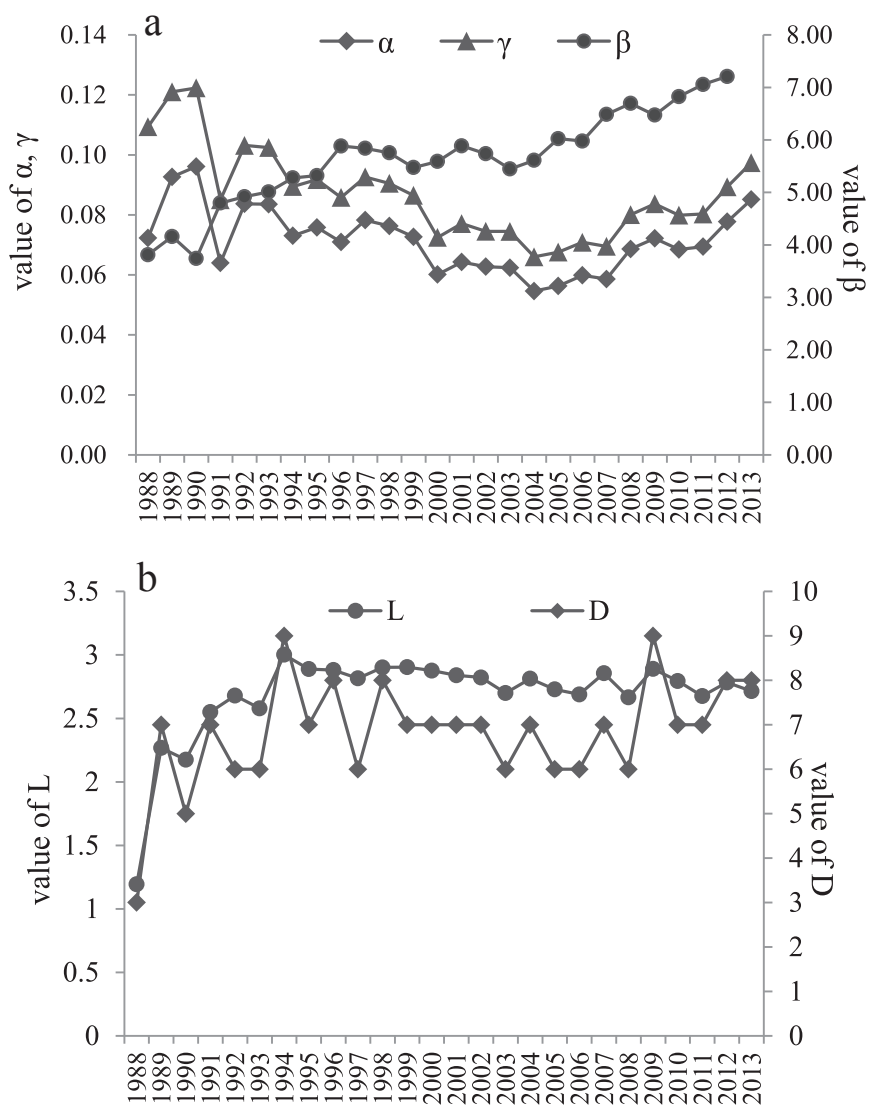

Fig. 2. a: Connectivity indices $(\alpha, \beta, \delta), 1988-2013$. b. Connectivity indices $(D, L)$, 1988-2013.

crises (Asia in 1997 and US in 2008) may have disrupted more complete linkage formation.

In contrast, $\beta$ displays a somewhat different trend. There is a general upward trend from 2.7 in 1988 to 7.2 in 2013 . Hence while $\alpha$ and $\gamma$ would seem to suggest that actual network connectivity may have contracted slightly between 1991 and 2013, the $\beta$ index on the other hand indicates that the spatial neighborhoods of countries have expanded. This is because $\beta$ measures the number of edges per node and so presents a slightly different interpretation of network connectivity. The upward trend is consistent with Fig. 1 that shows a greater number of edges over time. It also points to countries expanding their crude oil trade interactions with more markets and suppliers. Japan's import linkages or edges, for example, rose from 18 in 1988 to 28 in 2013. Similarly, a prominent exporting node like Saudi Arabia increased its number of edges from 10 in 1988 to 29 in 2013. Emerging countries such as India, Russia, Brazil and China all rapidly expanded their trade links with other countries over the twenty-six year period.

When examined in terms of $L$ and $D$, Fig. 2 b shows that the value of $D$ is lowest before 1990 . However the average path length $L$ also rose from 1.2 in 1988 to 2.7 in 2013. It is longest at 2.9 between 1999 and 2000 indicating that countries were trading with more distant partners over time. Taken together, $D$ supports $\alpha$ and $\gamma$ that the oil network was relatively more connected than presently in the early 1990s. However, because the number of edges of expanded between more distant partners, the average path length has also increased indicating that trade interactions have become flatter and more spatially dispersed.

\subsection{Spatial analysis of network centrality}

In this section, we turn to GIS (geographical information system) to visualize spatial patterns of the global crude oil networks. In order to facilitate interpretation, three representative years, that is 1990, 2000, 2013, will be presented to illustrate the evolution of networks over time. ${ }^{1}$ To shed light on the spatial structure of networks and the major hubs that occupy central positions on the networks, centrality indices based on degree $k$ and strength $s$ are examined (equations (6) and (7)).

Fig. 3a shows that the overall network is relatively sparse in 1990 because the number of edges was lower as fewer countries were involved in the trading system at this time (see Fig. 1). Nonetheless ten distinctive hubs may be identified using centrality measure total degree $k$ (Table 1 ). They are Germany, Spain, Japan, Australia, South Korea, Saudi Arabia, Canada, United Arab Emirates (UAE), Malaysia and Singapore in that order. The ten countries are responsible for $39 \%$ of all total edges. When disaggregated in terms on $k^{\text {in }}$ and $k^{\text {out }}$, the table shows that a regional small-world bloc may be detected among exporters $\left(k^{\text {out }}\right)$ in the Middle East (Saudi Arabia, Oman, UAE, Iran, Iraq, Kuwait). The six oil exporters are well-endowed with the resource and account for $32 \%$ of all edges. They are long-established oil suppliers as members of OPEC. In

\footnotetext{
${ }^{1}$ Maps for other years are available upon request from the authors.
} 

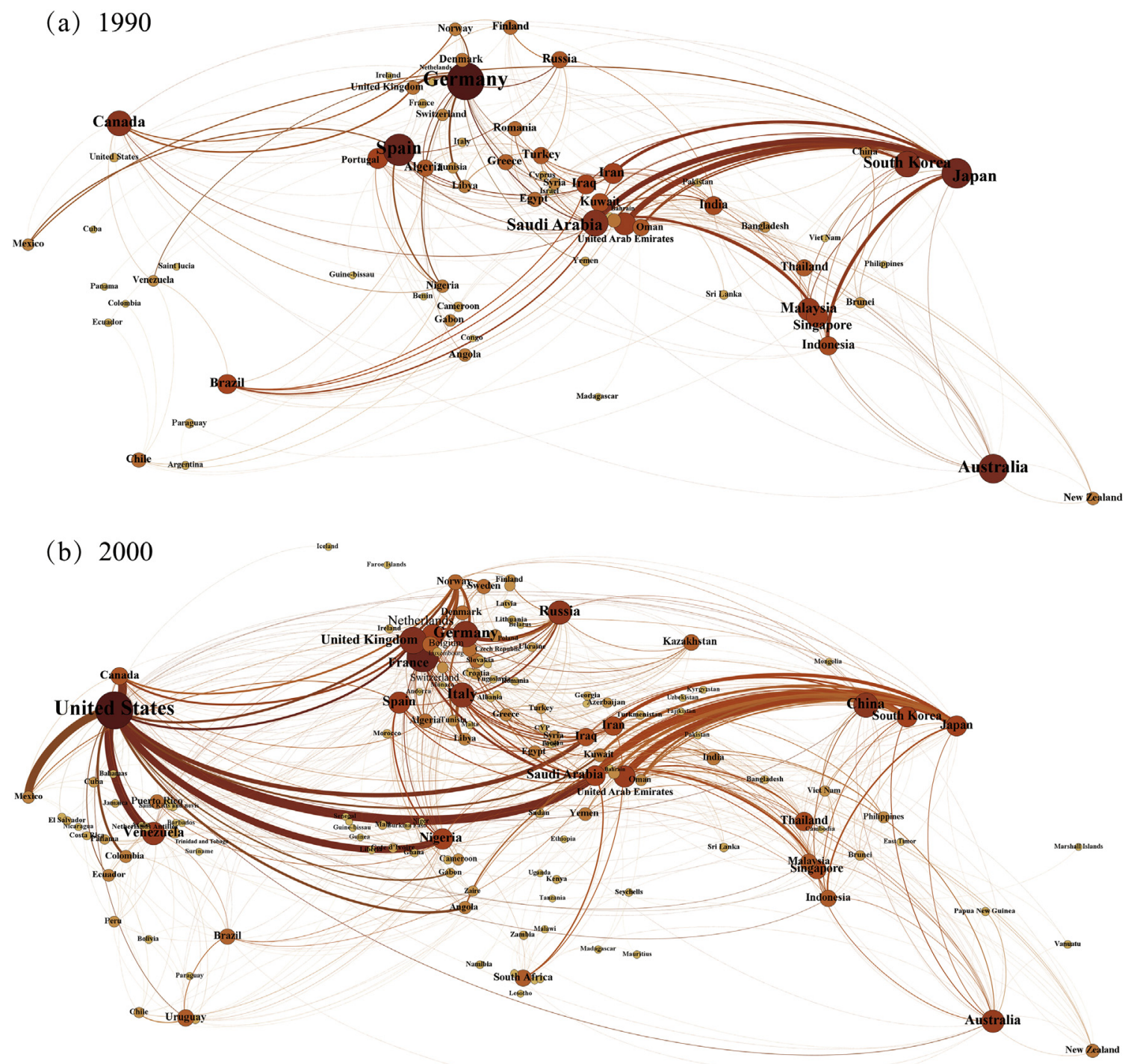

(c) 2013

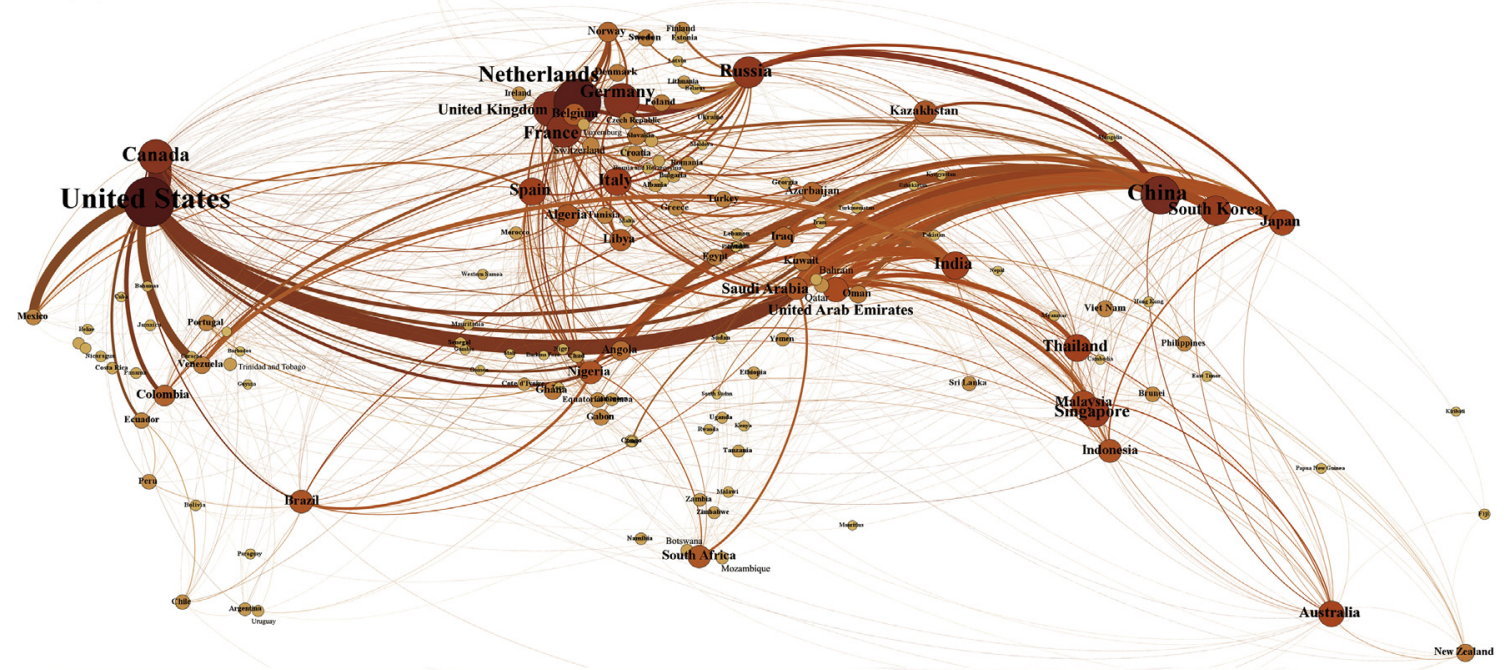

Note: node size captures $k$ size while thickness of lines indicates the weight of edges.

Fig. 3. Spatial structure of crude oil trade networks (1990, 2010, and 2013). 
Table 1

Degree $(k)$ and strength $(s)$ indices of top 10 countries, 1990, 2010 and 2013.

\begin{tabular}{|c|c|c|c|c|c|c|c|c|c|c|c|c|c|c|c|c|c|c|}
\hline \multicolumn{7}{|c|}{ No. Degree $(k)$} & \multicolumn{6}{|c|}{ In-degree $\left(k^{\text {in }}\right)$} & \multicolumn{6}{|l|}{ Out-degree $\left(k^{\text {out }}\right)$} \\
\hline & \multicolumn{2}{|l|}{1990} & \multicolumn{2}{|l|}{2000} & \multicolumn{2}{|l|}{2013} & \multicolumn{2}{|l|}{1990} & \multicolumn{2}{|l|}{2000} & \multicolumn{2}{|l|}{2013} & \multicolumn{2}{|l|}{1990} & \multicolumn{2}{|l|}{2000} & \multicolumn{2}{|l|}{2013} \\
\hline & Country & Value & e Country & Value & e Country & Value & Country & Value $C$ & Country & Value $\mathrm{C}$ & Country & Value & Country & Value & Country & Value & Country & Value \\
\hline 1 & Germany & 33 & United States & 73 & United States & 90 & Germany & 28 & $\begin{array}{l}\text { United } \\
\text { States }\end{array}$ & 43 & Netherlands 6 & 60 & Saudi Arabia & 21 & Russia & 36 & United States & 48 \\
\hline 2 & Spain & 27 & France & 58 & Netherlands & 83 & Spain & 27 & France & 37 & China & 45 & $\begin{array}{l}\text { United Arab } \\
\text { Emirate }\end{array}$ & 17 & Nigeria & 33 & Russia & 47 \\
\hline 3 & Japan & 25 & $\begin{array}{l}\text { United } \\
\text { Kingdom }\end{array}$ & 47 & China & 65 & Japan & 23 & Italy & 34 & $\begin{array}{l}\text { United } \\
\text { States }\end{array}$ & 42 & Iran & 15 & Saudi Arabia & 32 & United Kingdom & 37 \\
\hline 4 & Australia & 24 & Germany & 45 & $\begin{array}{l}\text { United } \\
\text { Kingdom }\end{array}$ & 59 & $\begin{array}{l}\text { South } \\
\text { Korea }\end{array}$ & 21 & China & 32 & Canada & 40 & Iraq & 14 & United Kingdom & 31 & $\begin{array}{l}\text { United Arab } \\
\text { Emirates }\end{array}$ & 35 \\
\hline 5 & South Korea & 21 & China & 42 & Canada & 57 & Canada & 18 & South Korea 2 & 28 & South Korea 4 & 40 & Kuwait & 13 & United States & 30 & Nigeria & 31 \\
\hline 6 & Saudi Arabia & 21 & Italy & 42 & Germany & 57 & Australia & 15 & Spain $\quad 2$ & 27 & France 3 & 37 & Algeria & 11 & Venezuela & 27 & Saudi Arabia & 29 \\
\hline 7 & Canada & 20 & Russia & 40 & France & 56 & Portugal & 15 & Germany & 26 & Singapore & 36 & Oman & 11 & Iran & 27 & Kazakhstan & 28 \\
\hline 8 & $\begin{array}{l}\text { United Arab } \\
\text { Emirates }\end{array}$ & 17 & Venezuela & 38 & Russia & 49 & Brazil & 14 & Japan & 24 & Spain & 35 & Russia & 11 & Iraq & 26 & Libya & 28 \\
\hline 9 & Malaysia & 17 & Australia & 37 & South Korea & 46 & Singapore & 13 & Netherlands & 22 & India & 34 & Malaysia & 10 & $\begin{array}{l}\text { United Arab } \\
\text { Emirates }\end{array}$ & 22 & Algeria & 25 \\
\hline 10 & Singapore & 16 & Spain & 35 & Singapore & 45 & India & 11 & Singapore & 22 & Thailand & 34 & Australia & 9 & France & 21 & Iraq & 25 \\
\hline \multicolumn{7}{|c|}{ No. Strength $(s)$} & \multicolumn{6}{|c|}{ In-strength $\left(s^{i n}\right)$} & \multicolumn{6}{|l|}{ Out-strength $\left(s^{\text {out }}\right)$} \\
\hline & 1990 & & 2000 & & 2013 & & 1990 & & 2000 & & 2013 & & 1990 & & 2000 & & 2013 & \\
\hline & Country & Value & Country & Value & Country & Val & lue Country & Value & Country & Value & le Country & Value & Country & Value & Country & Value & e Country & Value \\
\hline 1 & Japan & 305 & United States & 945 & United Kingdom & 28 & 43 Japan & 305 & $\begin{array}{l}\text { United } \\
\text { States }\end{array}$ & 940 & $\begin{array}{l}\text { United } \\
\text { States }\end{array}$ & 2792 & 2 Saudi Arabia & 172 & Saudi Arabia & 573 & Saudi Arabia & 2764 \\
\hline 2 & Saudi Arabia & 172 & Saudi Arabia & 573 & Saudi Arabia & 27 & 64 Germany & 127 & Japan & 446 & China & 2197 & $\begin{array}{l}7 \text { United Arab } \\
\text { Emirates }\end{array}$ & 114 & Norway & 287 & Russia & 1813 \\
\hline 3 & Germany & 127 & Japan & 446 & China & 215 & 98 Spain & 74 & South Kore & ea 253 & India & 1481 & 1 Iran & 88 & Russia & 243 & $\begin{array}{l}\text { United Arab } \\
\text { Emirates }\end{array}$ & 1037 \\
\hline 4 & $\begin{array}{l}\text { United Arab } \\
\text { Emirates }\end{array}$ & 114 & Norway & 289 & Russia & 18 & 15 Singapore & 69 & Germany & 220 & Japan & 1458 & 3 United Kingdom & 51 & Nigeria & 209 & Iraq & 856 \\
\hline 5 & Iran & 88 & South Korea & 253 & India & $14 \varepsilon$ & 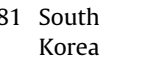 & 54 & France & 176 & South Korea & a 994 & 4 Indonesia & 46 & $\begin{array}{l}\text { United Arab } \\
\text { Emirates }\end{array}$ & 202 & Nigeria & 817 \\
\hline 6 & Spain & 74 & Russia & 249 & Japan & 14 & 59 Brazil & 49 & Italy & 171 & Germany & 743 & 3 Iraq & 44 & Iran & 197 & Canada & 811 \\
\hline 7 & Singapore & 69 & $\begin{array}{l}\text { United } \\
\text { Kingdom }\end{array}$ & 238 & Canada & 10 & 73 Canada & 46 & China & 149 & Netherlands & s 521 & 1 Libya & 42 & Venezuela & 172 & Kuwait & 708 \\
\hline 8 & Indonesia & 58 & Germany & 224 & $\begin{array}{l}\text { United Arab } \\
\text { Emirates }\end{array}$ & 10 & 37 Turkey & 35 & Netherlands & ds 122 & Italy & 465 & 5 Nigeria & 41 & Iraq & 162 & Angola & 635 \\
\hline 9 & South Korea & 54 & Canada & 223 & South Korea & 94 & 99 India & 34 & Spain & 116 & France & 457 & 7 Oman & 39 & United Kingdom & 160 & Venezuela & 595 \\
\hline 10 & United Kingdom & 51 & NGA & 209 & Iraq & 8 & 56 ROM & 23 & Canada & 93 & Spain & 453 & 3 Russia & 36 & Mexico & 147 & Norway & 493 \\
\hline
\end{tabular}

Note: strength unit is in US\$ billion. 
contrast, the top importing hubs $\left(k^{\text {in }}\right)$ are much less concentrated geographically dispersing across Europe and Asia. Importing hubs include Germany, Spain, Portugal, Japan, Australia, South Korea, Portugal, Brazil, Singapore and Canada. These 10 importing hubs account for half of the number of edges. The manufacturing sector in West Germany, Japan, South Korea and Singapore was in full steam in 1990 generating demand for energy. These countries tend to be poor in resources and are heavily dependent on external sources of crude oil. Spain has very little oil and gas production domestically and is a big importer of crude oil. Not surprising, Fig. 3a shows a relatively heavy corridor of crude oil flows between Japan, South Korea, Singapore, Malaysia, and, the Middle East. Likewise Germany and Spain are centrally positioned in Europe by virtue of their import partnerships with countries around the region and immediately beyond.

The picture is somewhat different in 2000 as the number of countries that participated in the oil trade increased to 150 (Fig. 3b). Crude oil flows intensified between Japan, South Korea and the Middle East. In Europe, Germany and Spain's previous structural dominance has been displaced by France and United Kingdom (UK). At the same time, Italy has emerged as a major hub. Europe's centrality in world crude oil trade has become more obvious supported by a triadic pattern of hub importance between the above three countries. The most significant structural change however is associated with the meteoric rise of the US and China hubs with US supplanting Germany as the top hub. Their central hub position is predominantly explained by a high value of $k^{i n}$ as the world's two largest consumers of energy today. It is worth noting that all of the top ten importing hubs have by this time expanded their geographical neighborhoods so that concomitant patterns of small and flat worlds are becoming apparent. The US for instance has not only built considerable links with its neighbors in Latin America, but also across the Atlantic to Nigeria, the Middle East and Europe.

Likewise, France, Germany and Italy are highly linked not only with oil exporting countries like Norway and Russia, but also with North Africa and the Middle East. Meanwhile, the corridor between Japan, South Korea, and, the Middle East has intensified as illustrated by thicker flow lines in Fig. 3b. But Table 1 also shows that the two East Asian countries have dropped off from the top ten $k$ hub list. One explanation is that they have not expanded their trade linkages as quickly as the US or UK, preferring to focus more narrowly on established supply partners in the Middle East. Nonetheless, both Asian countries have begun a strategy of outward investment to Southeast Asia by this time enabling them to retain top ten status in $k^{\text {in }}$. Singapore is an interesting import hub. Like its northern neighbors, it is also resource-poor. However, it is an international financial city and is home to one of the world's busiest ports. A significant amount of East and Southeast Asia's oil transactions are handled in Singapore. Oil shipments require hundreds of millions of dollars in financing, and Singapore's financial infrastructure and port facilities are relatively well-developed to support financing and coordinate transshipments.

The year 2000 also saw the increased prominence of oil exporting hubs from non-Gulf countries such as Venezuela and Russia. One outcome of increased sources outside of the Gulf region, along with new demand from US, China and the Netherlands, is that the top ten hubs now form less than $25 \%$ of total edges. This implies a trend of spatial decentralization, increased flatness and dispersion, and decreased connectivity that are consistent with the previous section.

Fig. 3c shows that crude oil flows have become more complex in 2013. There appears to be four regions - an observation that will be further quantified and elaborated in the next section - centered on Europe, Americas, Middle East, and to a lesser extent, the Asia Pacific. Within Europe, both Eastern Europe and Northern Africa have become integrated into the European regional neighborhood. The Netherlands has climbed to second place in $k$ hub ranking. The US retains its prominent central position while China is now third followed by UK. Spain, Italy, Australia and Venezuela have fallen off while Canada and Singapore are reinstated in the top ten. France and Germany's centrality has also fallen. European countries' diminished position may be due to a decrease or leveling off in energy consumption. Statistics from EUROSTATS indicate that energy consumption of the 28 countries of European Union in 2013 peaked in 2005 before falling and stabilizing in 2013. Notably, members' energy consumption in 2013 was 1667 million tons which is the same level as 1990 . Less and less of the members' energy needs are being met by oil while $20 \%$ is expected to come from renewable sources by 2020. In the Middle East and North Africa, Saudi Arabia, Iraq, UAE, Libya and Algeria remain strong exporting hubs as demonstrated by their $k^{\text {out }}$ values. Notably, Kazakhstan of Central Asia has emerged as a new export hub. With its addition to the top ten hubs, the supply network is now the most diversified geographically compared to previous years.

Interestingly, the US became the most central export hub in 2013 with forty-eight trading edges. The boom in US crude oil exports began in 2008 reversing previous trends with the extraction of shale oil from North Dakota and Montana. Russia's exporting status has also surpassed Gulf countries like Saudi Arabia and UAE in part because it has aggressively expanded its export neighborhood beyond Europe to the Asia Pacific. Meanwhile, oil from the North Sea continues to strengthen UK's central position. Turning to $k^{\text {in }}$, the Netherlands, China, US, Canada and South Korea occupy the top five central positions. While three of the five countries are oil producers, they also import oil because domestic consumption exceeded domestic production. In 2013 for example, US and China produced 446.2 and 208 million tons of oil. But their respective consumption of 831 and 507 million tons had to be met by imports. Canada is slightly different as it produces more oil than it consumes. Nonetheless, as Coy has pointed out [29], Eastern Canada imports oil from Texas in the US because its delivery infrastructure (that is oil pipelines) favors exports to the US encouraging northsouth flow than east-west flows within Canada. At the same time, India and Thailand have become prominent import hubs. The results indicate that importing nodes are pursuing a wider spatial range of suppliers. The centrality of the Netherlands for instance is associated with its large number of import partners, that is, 60 .

The tendency to export to a greater number of markets, and import from a wider number of supplying countries explains why total $k$ value in 2013 is nearly 4 times higher than that of 1990 . The centrality of import and export hubs has thus strengthened over the 26 years. And as the connectivity indices in the previous section suggest, network expansion is accompanied by increased connectivity after the mid-2000s. In turn, increased connectivity facilitates the intensification of crude oil flows as Fig. 3c shows. Major corridors of flows that dominate include the US-Middle East, East AsiaMiddle East, and Europe-Russia.

Besides $k$ measures, the central positioning of hubs may also be understood through strength $s$ indices. Strength may better capture the importance of a node to the whole network because it is estimated from actual flows. Table 1 shows that $s$ presents a slightly different picture. $s$ and $k$ rankings of the largest ten hubs are least varied in 1990. Strength is highest for Japan followed by Saudi Arabia, Germany, UAE, Iran, Spain, Singapore, Indonesia, South Korea and Spain. Japan's $s$ of 305 compared to its $k$ of 25 shows that its oil trade strength with partners is stronger even though it's number of partnerships and links is lower. Conversely, Germany is now ranked third despite a higher $k$ of 33 because its $s$ value is lower at 172. Likewise, Table 1 shows that Saudi Arabia and UAE are ranked higher under $s$, and along with Indonesia, have displaced 
Canada and Malaysia which are no longer in the top ten. When disaggregated, the top ten's position of strength may be explained by differences in values of $s^{\text {in }}$ and $s^{\text {out }}$. Germany, Spain, Japan, Singapore and South Korea all register high $s^{\text {in }}$. In contrast, Saudi Arabia and UAE register high values of $s^{\text {out }}$ at 172 and 114 . Clearly hub positions are a function of the countries' dominance as exporters or importers not unalike $k$. Interestingly, the strength measure identified India, Romania and Turkey as important import hubs as early as 1990 .

In 2000, Japan continues to be ranked highly under $s$, and so are Nigeria and Norway. The US remains a top hub influenced by a high $s$ value of 940 , led by a strategy to reduce its oil dependency on the Middle East. China, on the other hand, is ranked at seven compared to four under $k$. The Middle East continues to dominate in export strength and Mexico is included in the top ten. On the export side, while the rankings are slightly different from $k$, nonetheless, Germany-France-Italy's triadic dominance in Europe remains unchallenged. Likewise, the US-Saudi Arabia central position is unchanged. Compared to $k$ distribution, emerging economies including India and Russia are ranked higher. On the import side, US and East Asia have forged strong networks with importing nodes, while on the export side, Nigeria, Russia and key OPEC members continue to maintain their centrality. However one major difference between $k$ and $s$ rankings is that Kazakhstan has slipped to thirteen while Angola has risen to eight in ranking.

Overall, both $s$ and $k$ values suggest that the US, China, UK, Russia, and to a lesser extent, Canada, are important players in the global crude oil trade today. Large oil exporters from the Middle East like Saudi Arabia and UAE have largely been able to hold on to their central export positions but Nigeria, Russia and Venezuela have made much inroad expanding their network neighborhoods. Clearly importing countries are diversifying their country sources to avoid risks of supply interruptions while exporting nodes are building more flexible and distant relationships in search of markets.

\subsection{Modularity and community structure}

Analysis of the spatial structure of countries' centrality, specifically hub leadership, in the previous section points to both the presence of small worlds and also distant partnerships. To quantify these relationships, we apply equation (8) that partitions communities based on the density of edges within communities compared to edges between communities. Fig. $4 a-c$ provide a geovisualization of such communities by mapping them for years 1990, 2000 and 2013.

From equation (8), four communities may be identified for 1990 and 2000, and five for 2013. These communities display regional characteristics of small worlds which is consistent with the clustering pattern found by Zhang and his colleagues [30]. But they also reveal properties of flat dispersed worlds. While two regions appear discernible (Europe and the Middle East), the community structure of 1990, for the most parts, displays a relatively diffused pattern of oil trade flows than regionalized pattern. Tunisia, Mexico, Canada and the US, for instance, are in the same community with Western Europe (Europe-America-Africa community). Likewise, Southeast Asia is in the same community with major oil hubs in the Middle East like Saudi Arabia (Middle-East-Southeast Asia), while Japan, China and South Korea are conjoined with Oman, Kuwait and Bahrain (Middle East-East Asia). Australia, Brazil and Romania are also assigned to this "region". In effect, the Asia Pacific region is split into two regions because of their different geographical orientations to exporting hubs in the Middle East. Interestingly, 1990 also saw a small world region in South America comprising Argentina, Ecuador, Chile and Colombia.
By 2000, the NAFTA bloc had broken off from the Western European region to form its own regional hub, drawing many Latin American countries into its spatial fold ("Americas" in Fig. 4b). By virtue of their ties to South American countries like Brazil and Mexico, Spain and Portugal also became part of the Americas. Across the Atlantic, a European Union bloc is visible as western, northern, southern and eastern European countries amalgamated (Europe-Central Asia-Africa community). This is the largest "small world" region with 51 country members assigned to it. Because industrialized countries here are relatively dependent on Russia for oil, the country is connected to this community. Northern Africa is also part of the community from long-standing historical and colonial ties. In Asia, East and Southeast Asia have become more integrated driven by intensifying division of labor arising from intra-regional investment. Japan, Singapore, Taiwan and South Korea for instance had relocated labor-intensive industries to China and Southeast Asia by this time spurring a demand for energy in the region. Asia Pacific and Middle East are also conjoined in the same community facilitated by East Asia's poorly endowed energy resources. Despite increased integration, the region continues to be split into two regions consisting of Middle East-East Asia and Middle East-Southeast Asia. The final fourth community consists of four members from Central Asia. Unlike their neighbor Kazakhstan, many countries in this region are still poorly connected to other countries and remain the smallest small world among the four communities.

The above discussion of Fig. 4b indicates that distinct small worlds have begun to form in 2000 although membership of each small world community varies. But community regional membership is not always stable. In 2013, the Americas have become less clustered and regionalized than the previous period. US remains the largest sized node, hence the US-centered Americas continue to form a region with Venezuela, Central America, and also with East Africa. Canada in the north and Argentina, Brazil, Chile, Mexico and Peru in the south were re-assigned to the European region (Europecentered America-Central Asia-Africa community). Regional blocs have begun to assume what might be considered the spatial form of a "networked community" with flows extending to Africa, the Middle East and Asia capturing US' strategic diversification from geographically scattered oil partners. The strengthening geopolitical relationship between Saudi Arabia and the US also facilitated a break away from East Asia that had previously seen strong ties between Saudi Arabia and East Asia.

Nonetheless, geography is not absent in 2013 with Europe exhibiting the strongest regional clustering tendency (Fig. 4c). Indeed this region is so big that it covers most of Europe as well as Central Asia and North Africa. Notably, NAFTA countries Canada and Mexico as well as ex-colonies from Africa are now part of the European community. In Asia, an interesting pattern has emerged. East and Southeast Asia have continued to deepen their regional ties between themselves and with several Gulf countries (Middle EastAsia community). However, China is now part of a separate community. China has aggressively sought to meet its prodigious energy demand by investing in Africa in addition to the Middle East. Consequently, a new community centered on China has emerged with membership that is made up largely of developing countries particularly from Africa (China-Middle East-Africa community). Finally a small fifth community may be identified but it may be because the countries are poorly connected to any of the other four regions. The fifth community is a very small world consisting of just three countries, namely Slovenia, Nicaragua and Curaçao.

Overall analysis of the community structure reveals both small and flat world properties. The European region for instance is composed of close geographical, cultural and historical ties that unite many countries on the continent in their oil interactions. On the 
(a) 1990

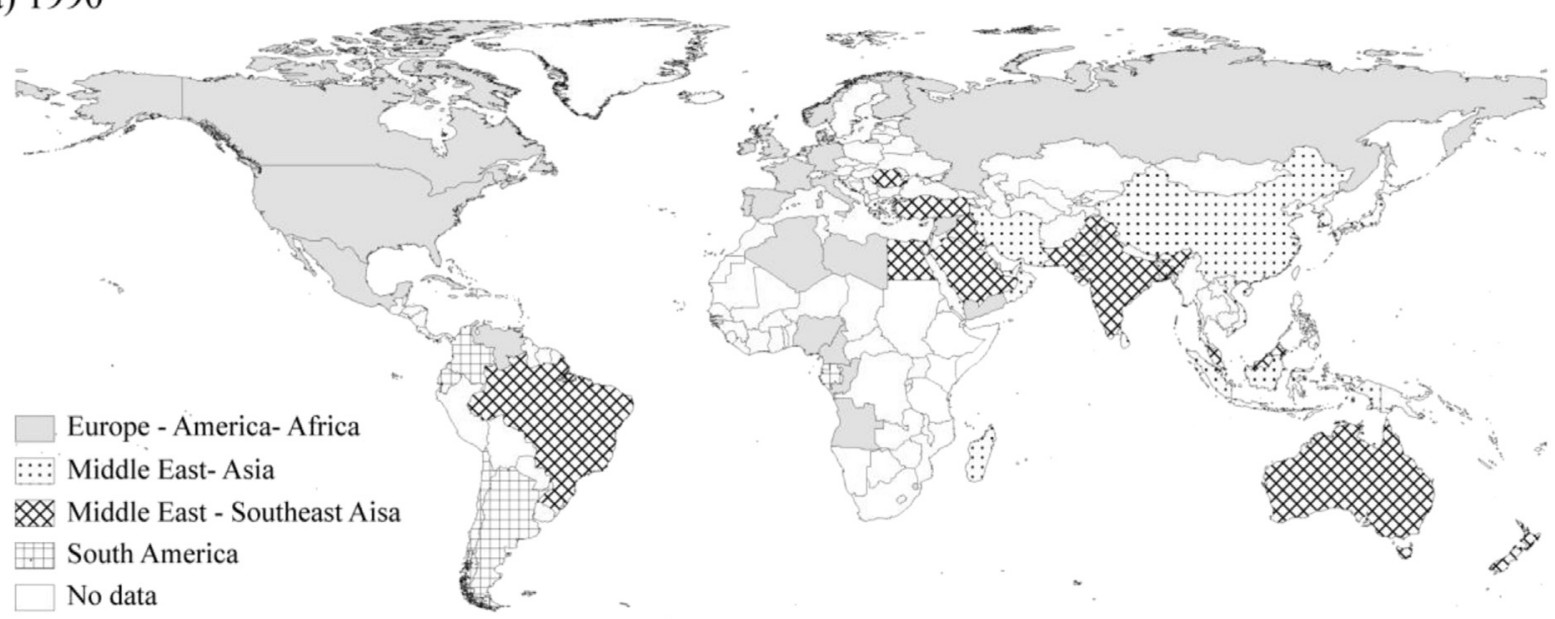

(b) 2000

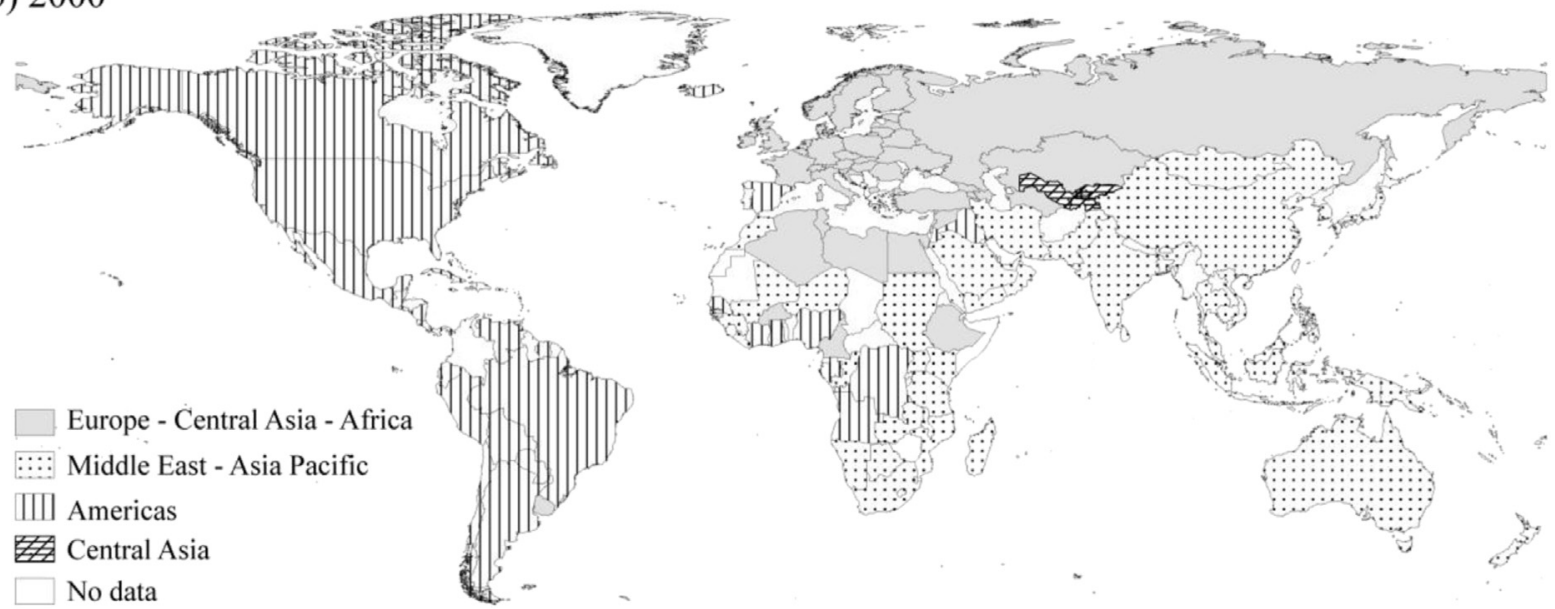

(c) 2013

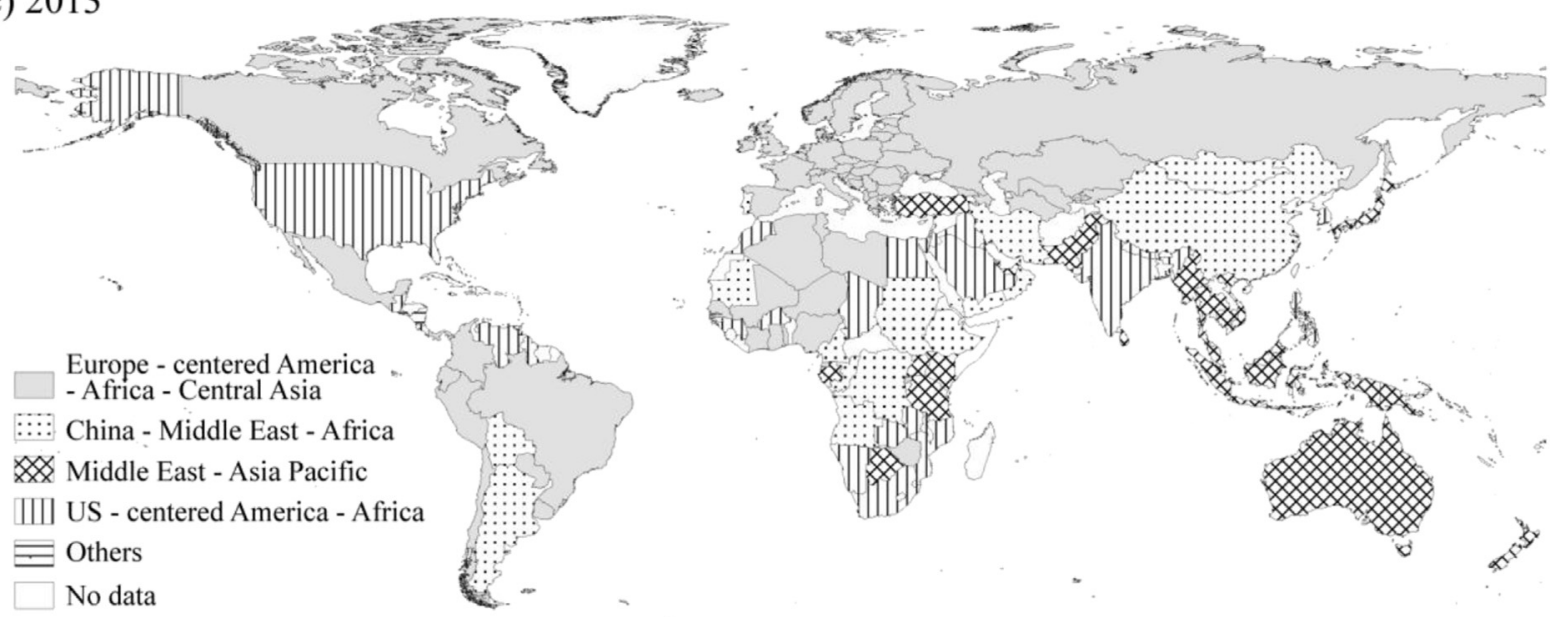

Fig. 4. Community structure of crude oil trade flows (1990, 2010, 2013).

other hand, as dominant oil suppliers, countries in the Middle East are more likely to pursue geographically disperse trade relationships including partners in Europe, North America and East Asia.

\section{Conclusion}

Applying scale-free network analysis to crude oil trade flows from 1988 to 2013, this paper finds evidence that both small and flat world interactions underscore the spatial structure of the trading system. As countries established more distant partnerships over time, the average length of the network rises. But they also decrease actual to maximal connectivity, particularly in the early to mid-2000s. One explanation may lie in spatial fragmentation as neighboring countries disperse their trading relationships to decrease their dependence on a few suppliers, or, to expand the scope of their markets. However, political and economic turmoil 
also explains the dynamic nature of the networks. The power of distance continues to be expressed through its effect on small world clusters with a consistent bloc centered on Europe throughout the period. Other clusters are less stable; nonetheless, two consistent cluster corridors may be detected between the Middle East and East Asia/Southeast Asia.

While some of the strongest and most intense crude oil flows are among neighboring countries, strong connections across the Pacific and Atlantic are also visible giving rise to networked communities. Such networked communities appear to be most conspicuous in the US and China-led hubs. One benefit of networked communities is that distant developing countries may now join the supply chains of hub countries like the US providing prospects of economic development. The number of countries participating in the world oil network increased twofold just between 1990 and 2000. Many of the new entrants were developing countries from Africa and Latin America. Similarly, the value of $k$ and $s$ also more than doubled over the ten years. Network externalities provide access to the markets of North America and Europe. They also increase possibility of information sharing between firms who are embedded in the trade networks of the communities.

One implication of the results is that there are distinct coreperipheral relationships: global crude oil trade is dominated by the presence of just fifteen hubs that account for nearly half of all connections or edges. The concentration of trade linkages is even higher among the top ten hubs. Some hubs like Russia, Saudi Arabia and the UK have strengthened rather than diminished in strength over time. Meanwhile China and the US remain the largest hubs in terms of degree size. As more countries industrialize and join the global economy, it is expected that the world oil trade will continue to display flat world properties. Yet neighboring countries will also continue to gravitate to one another, and consolidate their small world relationships.

\section{Acknowledgments}

Support from the National Natural Science Foundation of China under Grant No. 41401132, No. 41371141 and No. 41430636 is acknowledged. The authors also appreciate financial support provided by the China Scholarship Council.

\section{References}

[1] BP. BP statistical review of world energy. 2014.

[2] Barigozzi M, Fagiolo G, Garlaschelli D. Multinetwork of international trade: a commodity-specific analysis. Phys Rev E 2010;81(4):1-23.
[3] Costa LD, Rodrigues FA, Travieso G, Boas PRV. Characterization of complex networks: a survey of measurements. Adv Phys 2007;56(1):167-242.

[4] Fagiolo G, Reyes J, Schiavo S. On the topological properties of the world trade web: a weighted network analysis. Phys A Stat Mech Appl 2008;387(15): 3868-73.

[5] Fagiolo G, Reyes J, Schiavo S. The evolution of the world trade web: a weighted-network analysis. J Evol Econ 2010;20(4):479-514.

[6] De Benedictis L, Tajoli L. The world trade network. World Econ 2011;34(8): $1417-54$.

[7] Garlaschelli D, Loffredo MI. Structure and evolution of the world trade network. Phys A Stat Mech Appl 2005;355(1):138-44.

[8] Milgram S. The small world. Psychol Today 1967;2(2):60-7.

[9] Watts DJ, Strogatz SH. Collective dynamics of 'small-world' networks. Nature 1998;393(6684):440-2.

[10] Uzzi B, Spiro J. Collaboration and creativity: the small world problem. Am J Sociol 2005;111(2):447-504.

[11] Rugman AM, Li J, Oh CH. Are supply chains global or regional? Int Mark Rev 2009;26(4-5):384-95.

[12] Lin FG. Are distance effects really a puzzle? Econ Model 2013;31:684-9.

[13] OECD. Implications of global value chains for trade, investment, devleopment and jobs. Paris. 2013.

[14] Friedman T. The world is flat: a brief history of the twenty-first century. 2nd ed. New York: Farrar, Straus and Giroux; 2007.

[15] Coe DT, Subramanian A, Tamirisa NT. The missing globalization puzzle: evidence of the declining importance of distance. Imf Staff Pap 2007;54(1): 34-58.

[16] Philip AS, Roland D. China, oil and global politics. New York: Routledge; 2011.

[17] O'Brien R. Global financial integration: the end of geography. New York: Council on Foreign Relations Press; 1992.

[18] Bremond V, Hache E, Mignon V. Does OPEC still exist as a cartel? an empirical investigation. Energy Econ 2012;34(1):125-31.

[19] Ji Q, Zhang HY, Fan Y. Identification of global oil trade patterns: an empirical research based on complex network theory. Energy Conv Manag 2014;85: 856-65.

[20] Zhong WQ An HZ, Gao XY, Sun XQ. The evolution of communities in the international oil trade network. Phys A Stat Mech Appl 2014;413:42-52.

[21] An HZ, Zhong WQ, Chen YR, Li HJ, Gao XY. Features and evolution of international crude oil trade relationships: a trading-based network analysis. Energy 2014;74:254-9.

[22] Disdier AC, Head K. The puzzling persistence of the distance effect on bilateral trade. Rev Econ Stat 2008;90(1):37-48.

[23] Wang J, Mo HH, Wang FH. Evolution of air transport network of China 1930-2012. J Transp Geogr 2014;40(S1):145-58.

[24] Wasserma S, Faust K. Social network analysis: methods and applications (structural analysis in the social sciences). New York: Cambridge University Press; 1994.

[25] Scott J. Social network analysis: a handbook. 2nd ed. London: SAGE Publications Ltd; 2000.

[26] Barigozzi M, Fagiolo G, Mangioni G. Identifying the community structure of the international-trade multi-network. Phys A Stat Mech Appl 2011;390(11): 2051-66.

[27] Newman MEJ. Modularity and community structure in networks. Proc Natl Acad Sci U S A 2006;103(23):8577-82.

[28] Leicht EA, Newman MEJ. Community structure in directed networks. Phys Rev Lett 2008;100(11):1-4.

[29] Coy P. Canada wonders why crude oil is coming from Texas. Bloomberg. March 15, 2013 [accessed 16.03.15], www.bloomberg.com/bw/articles/201303-15/canada-wonders-why-crude-oil-is-coming-from-texas.

[30] Zhang HY, Ji Q, Fan Y. Competition, transmission and pattern evolution: a network analysis of global oil trade. Energy Policy 2014;73:312-22. 